\title{
Elektrostatik toz boya uygulanmış ahşap esaslı levhaların bazı teknolojik özelliklerinin incelenmesi
}

\section{Investigation of some technological properties of wood-based boards coated with electrostatic powder coating}

\section{Memiş AKKUŞ}

Düzce Üniversitesi, Orman Fakültesi, Ağaç İşleri Endüstri Mühendisliği Bölümü, Konuralp, DÜZCE

Eser Bilgisi / Article Info

Araştırma makalesi / Research article DOI: 10.17474/artvinofd.994081

Sorumlu yazar / Corresponding author

Memiş AKKUŞ

e-mail: memisakkus@duzce.edu.tr

Geliş tarihi / Received

11.09.2021

Düzeltme tarihi / Received in revised form

29.10.2021

Kabul Tarihi / Accepted

01.11.2021

Elektronik erişim / Online available

18.11.2021

\section{Anahtar kelimeler:}

Elektrostatik toz boya

MDF

Yongalevha

Teknolojik özellikler

\section{Keywords:}

Electrostatic powder coating

MDF

Particleboard

Technological properties

\begin{abstract}
Özet
Elektrostatik toz boyalar, otomotiv ve beyaz eşya gibi iletken metalik yüzeyler üzerine uygulanmaktadır. Elektrostatik toz boyalar uçucu organik bileşik içermemesi, çevre, iş güvenliği ve işçi sağlığı açısından diğer sıvı boyalara göre daha avantajlıdır. Bu avantajlarından dolayı son zamanlarda iletken olmayan plastik, ahşap ve ahşap esaslı levhalara uygulanması yönünde birçok araştırma ve geliştirme faaliyetleri yürütülmektedir. Bu çalışmada ahşap esaslı levhalardan yongalevha ve orta yoğunlukta liflevha (MDF) yüzeylerinin iletkenlik değerini artırmak için ön ısıtma $\left(70^{\circ} \mathrm{C}\right)$ ve sonrasında korona tipi tabanca ile hibrit esaslı (Epoksi/Polyester) elektrostatik toz boya işlemi uygulanmıştır. Daha sonra örnekler, kızılötesi (infarared) fırınlarda $130^{\circ} \mathrm{C}$ sıcaklıkta 20 dakika boyunca kürlenme işlemine tabi tutulmuştur. Ön ısıtma ve kürlenme esnasında MDF ve yongalevhalarda ısının etkisi ile levhalarda mekanik ve fiziksel değişimler öngörülmektedir. Bu amaç doğrultusunda; elektrostatik toz boya uygulanmış ve uygulanmamış MDF ve yongalevha örneklerinin, TS 319 standardına göre iç yapışma direnci, TS EN 310 standardına göre eğilme direnci, TS EN 320 standardına göre vida çekme direnci, ASTM D 1037 standardına göre su alma oranı ve TS EN 317 standardına göre kalınlığına şişme testlerine tabi tutularak istatistiksel karşılaştırılması yapılmıştır. Yapılan karşılaştırma sonucunda, elektrostatik toz boya ile kaplanması MDF örneklerinde çok fazla değişikliğe neden olmaz iken, yongalevha örneklerinin mekanik ve fiziksel özelliklerini etkilediği tespit edilmiştir.
\end{abstract}

\begin{abstract}
Electrostatic powder coatings are applied on conductive metallic surfaces such as automotive and white goods. Electrostatic powder coatings are more advantageous than other liquid coatings in terms of environment, work safety and worker health, as they do not contain volatile organic compounds. Due to these advantages, many research and development studies have been carried out recently for the application of non-conductive plastic, wood and wood-based composite panels. In this study, hybrid-based (polyster/Epoxy) electrostatic powder coatings was applied to the surfaces of particleboard and fiberboard (MDF) by corona type spray gun after exposed of preheating $\left(70^{\circ} \mathrm{C}\right)$ to increase the electrical conductivity of surface of the wood-based boards. Then, the samples were cured in infrared ovens at $130{ }^{\circ} \mathrm{C}$ for 20 minutes. During pre-heating and curing, mechanical and physical changes are envisaged in MDF and particleboards with the effect of heat. In accordance with this purpose; The coated and uncoated of MDF and particleboard tested to the internal bonding strength, the bending strength, the screw resistance, the water absorption and the thickness swelling determined to according to TS 319, TS EN 310, TS EN 320, ASTM D 1037, and TS EN 317 standards, respectively. As a result of the comparison, it was determined that while application of electrostatic powder coating did not cause much change in MDF samples, it affected the mechanical and physical properties of the particleboard samples.
\end{abstract}

\section{GiRiş}

Günümüzde gelişen sanayileşme ile birlikte boyanın kuruma sürecinde çevreye salınan organik çözücülerin, çevre ve halk sağıı̆̆ı üzerindeki olumsuz etkileri hakkında farkındalık oluşmaya başlamıştır. Organik çözgen yayılımını azaltacak önlemleri içeren alternatif boya türleri ve uygulama yöntemlerine ilişkin arayışlar 1970'li yıllardan beri devam etmektedir. Polimer geliştirme alanında yapılan çalışmalar ve bunu izleyen boya araştırma çalışmaları, çevre dostu boya ürünlerinin çoğalmasına yol açmıştır. Bu çerçevede, az miktarda organik çözgen içeren yüksek katılı boyalar, çözgensiz sıvı boyalar, sulu boyalar ve toz boyaların uygulanma alanları giderek genişlemektedir (Tunçgenç 2004). Toz boyalar, temiz hava hareketi adı altında yapılan düzenleme sonucunda (Clean Air Act Amendments) tehlikeli hava kirleticiler (HAP's) ve uçucu organik bileşik (VOC) emisyon değerlerini önemli ölçüde azalttığından dolayı, sıvı solvent esaslı boyaların alternatifi durumundadır. Toz boyalar, diğer endüstriyel boyama sistemleri ile karşılaştırıldığında en düşük VOC içeren boya olarak karakterize edilebilir 
(Liberto 2003, Gioia ve ark. 2015, Wuzella ve ark. 2015). Çevre Koruma Ajansı (EPA), Toksik atıklar üzerinde çevresel kalite standartlarını "Temiz Hava Yasası" ile belirlemişler ve bu doğrultuda, EPA çevreye zararlı emisyonları azaltmak için toz boyama uygulamalarının yaygınlaşmasını teşvik etmektedirler (Utech 2002).

Avrupa solvent emisyon kuralları, tüketiciler ve üreticilerde artan ekolojik bilinçten dolayı, ekolojik ve ekonomik boyaların kullanımı gün geçtikçe büyük rağbet görmektedir. Çevreye ve insan sağlığına zarar vermeyen boyalar, yüksek solvent içeren nitrosellüloz esaslı, asit bazlı veya çift kompenantlı poliüretan esaslı boyaların yerine almaya başlamıştır (Şekil 1). Son zamanlarda, ahşap ve ahşap esaslı kompozit levhaların boyanması bakımından toz boyalar, su bazlı sistemler ve UV kurumalı son kat üst yüzey işlemleri tercih edilmeye başlanmıştır. Mobilya endüstrisi açısından toz boyama teknolojisi büyük bir potansiyel oluşturmaktadır. Bu alanda son 10 yıldır araştırma ve geliştirme faaliyetleri yürütülmektedir. Örneğin: Sıcaklığa duyarlı malzemelere uygun, düşük sıcaklıkta kürlenme yapabilen yeni toz boya formülasyonları geliştirilmekte ve elektriksel iletkenliği artırmak için spesifik yüzey muamele işlemleri yapılmaktadır (Jocham ve ark. 2011).

Jocham ve ark. (2011) yaptıkları çalışmada, orta yoğunlukta liflevhaların toz boyama işlemi esnasında katman oluşumunu geliştirmek için ön ısıtma işlemi gerçekleştirmişlerdir. Elektrik direnci, uygulanan sıcaklık ve rutubet miktarı toz boya uygulamasının geliştirilmesi açısından büyük önem arz ettiğini bildirmişlerdir. Bu amaçla, yeni çok yönlü bir yöntemle ön ısıtma esnasında elektrik direnç ölçümü (yüzey ve orta tabaka dirençleri) geliştirmişlerdir. Levha yüzey sıcaklığı yükselirken elektriksel direncinde ani düşüş gözlemlendiği ve kızılötesi fırından çıkmadan önce kısa süreliğine minimum seviyeye ulaştığını belirtmişlerdir. Yüzey direnci $3 \times 10^{10}$ $\Omega^{\prime}$ dan $8 \times 10^{8} \Omega^{\prime}$ e düşmüştür ve yüzey sıcaklığının düşmesiyle birlikte dirençte çok az bir yükselme meydana geldiği bildirilmiştir. MDF yüzeylerine tek kat UVkürlenmeli toz boya uygulaması sonucunda yüksek parlaklık değerleri elde edilmiştir (Knoblauch 2013). MDF, yongalevha ve kontrplak yüzeylerine iletkenlik değerini artırmak ve epoksi, polyester ve hibrit esaslı statik toz boya ile kaplanmasına olanak sağlamak için ön soğutma işlemi uygulamışlardır (Akkuş ve ark. 2019; Akkuş ve ark. 2021). Badila ve ark. (2014) Yongalevha yüzeylerine akçaağaç bambu, kayın, armut, meşe ve venge ahşap kaplamalar ile kaplamışlardır. Daha sonra yüzeylerine şeffaf yüksek reaktivite özelliği olan epoksi/polyester esaslı toz boyayı (Drylac serisi 530), $130{ }^{\circ} \mathrm{C}$ sıcaklıkta, 8 dakika boyunca presleyerek kürlenmesini sağlamışlardır. Transparan elektrostatik toz boya ile verniklenmiş ahşap kaplamalı yongalevhalarda, boya katmanın yapışma direnci çapraz kesim metodu belirlenmiş ve tüm ahşap kaplama türleri için, katman yapışma direncini "çok iyi" olarak derecelendirmişlerdir. Köhler ve ark. (2017) yaptıkları çalışmada, kayın, göknar ve MDF malzemelerine plazma modifikasyon işlemi uygulaması sonucunda yüzey enerjisinin artmasını sağlamışlar ve malzeme yüzeylerini polyester esaslı elektrostatik toz boya ile kaplamışlardır. Altuntaş (2012) yapmış olduğu buluşta; metal tozu, epoksi reçine ve hızlandırıcı maddelerden hazırlamış olduğu astar boyayı, iletken olmayan ürünlerin yüzeylerine uygulayarak malzeme yüzeylerinin iletkenlik değerini artırmıştır. Illetkenlik özelliği kazanmış malzeme yüzeylerine elektrostatik toz boya uygulamıştır. Ayrılmış (2020) Yönlendirilmiş yongalevha (OSB) yüzeylerini 5 dakika ön ısıtma işlemi uygulayarak OSB yüzeylerini elektrostastik toz boya ile kaplanmasına olanak sağlamıştır.

Kaplama çeşidi ve kaplamanın uygulama yöntemi, ahşap esaslı levhaların mekanik ve fiziksel özelliklerini etkilemektedir. Yongalevha yüzeylerine melamin reçine emdirilmiş kâğıt, ahşap kaplama ve CPL (Continuous Press Laminates) kaplanması sonucunda, kaplanmış yongalevhaların mekanik özelliklerini artırdığı ve suda bekleme neticesinde kalınlığına şişmeyi azalttı̆̆ı ifade edilmiştir. İstatistiksel olarak da kaplama tipi ve laminasyon tekniği yongalevhanın teknolojik özelliklerini etkilediği belirtilmiştir (Nemli ve Çolakoğu 2005, Nemli ve Hızıroğlu 2009). İstek ve ark. (2010) farklı reçine tipleri ve farklı dekor kâğıtları ile yongalevha yüzeylerini kaplamışlar ve çalışma sonucunda, reçine tipi ve farklı dekor kâğıtları, malzemenin teknolojik özelliklerini etkilediğini ifade etmişlerdir. Farklı bir çalışmada, yongalevha yüzeyleri çeşitli proseslerde reçine emdirilmiş kâğıt ile kaplanmış ve kaplamasız yongalevhalar ile karşılaştırılması sonucunda, eğilme direnci ve elastikiyet modülünde artış, iç yapışma direnci ve vida çekme direncinde ise düşüş olduğu bildirilmiştir (İstek 2016). Lake boyama, melamin reçine emdirilmiş kağıt kaplama, ahşap kaplama ve CPL (continuous press laminates) ile kaplanmış yongalevha örnekleri arasında iç yapışma direnci bakımından istatiksel bir fark bulunmadığı ifade edilmiştir (Nemli ve ark. 2005). 


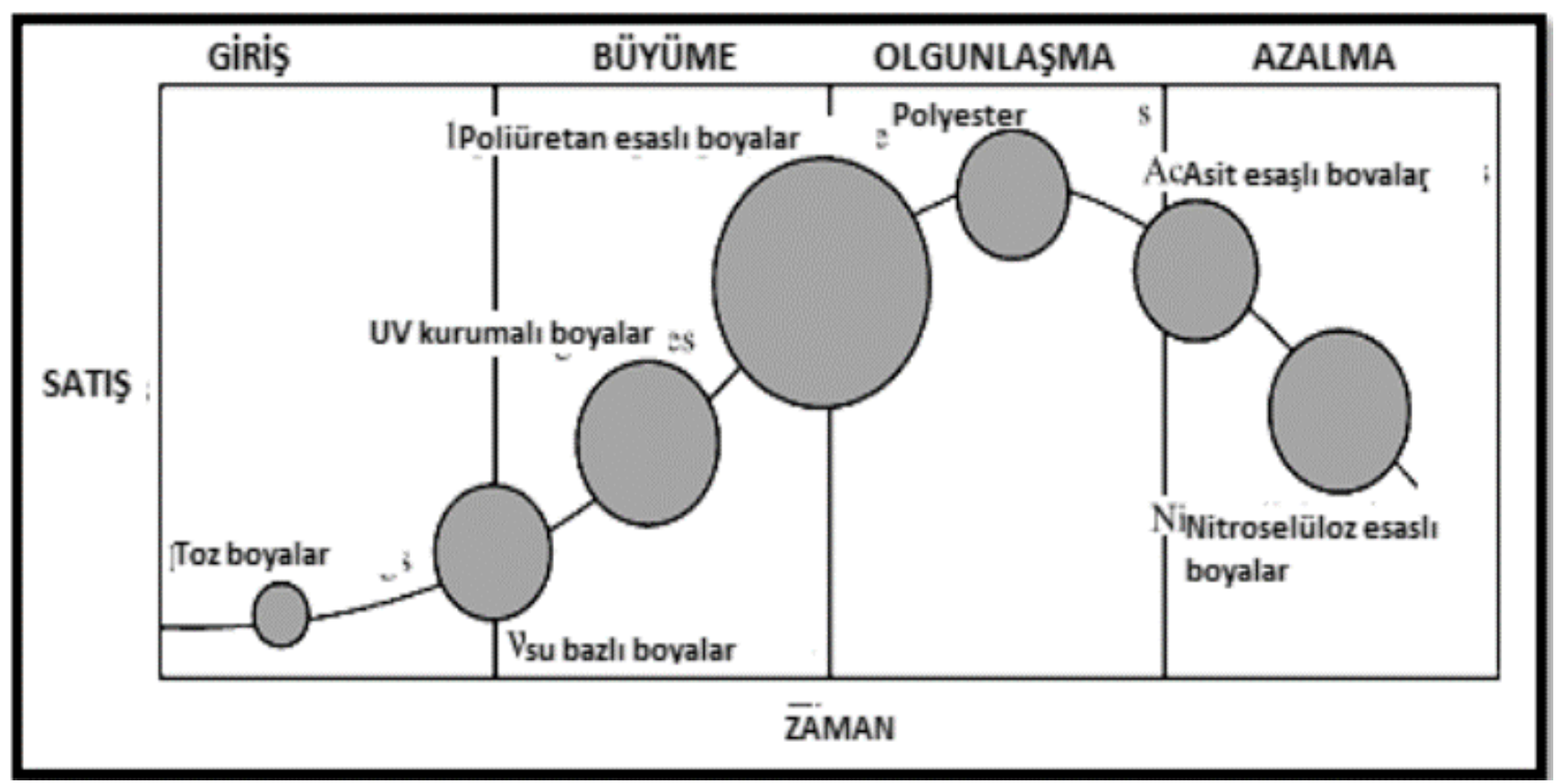

Şekil 1. Ahşap ve ahşap esasıı levhalarda uygulanan farklı boyama teknolojilerinin zamana göre ürün kullanım döngüsü (Jocham ve ark. 2011).

Literatürde, ahşap esaslı levhalara uygulanan ısıl işlemin (post-heat treatment) levha özelliklerini etkilediği belirtilmektedir. Farklı sıcaklıkta $\left(155^{\circ} \mathrm{C}, 165^{\circ} \mathrm{C}\right.$ ve $\left.175^{\circ} \mathrm{C}\right)$ ve farklı sürelerde $(2.5,3.5$ ve 4.5 saat) MDF levhalara uygulanan isıl işlem sonucunda eğilme direnci ve eğilmede elastikiyet modülü olumsuz etkilediği, kalınlığına şişme, su alma oranı ve formaldehit emisyon değerlerini olumlu yönde etkilediği ifade edilmiştir (Ateş ve ark. 2017). Dış ortam şartlarında kullanılan MDF örneklerine yapılan ısıl işlem sonucunda kalınlığına şişme özelliğinde iyileşme meydana gelirken, su alma oranında artışa neden olduğu ve ısıl işlem sıcaklığının artması ile birlikte eğilme direnci ve eğilmede elastikiyet modülünde azalma tespit edilmiștir (Ayrılmış 2009). Yongalevha, OSB ve MDF örnekleri $140{ }^{\circ} \mathrm{C}$ sıcaklıkta bir saat süre ile ısıl ișleme maruz kalması sonucunda eğilme direnci değerinin, yongalevhada \% 40, MDF'de \% 37 ve OSB'de \% 30 oranında azalmasına neden olduğu bildirilmiștir (Bektha ve ark. 2003). Hem fırın hem de sıcak preste farklı sıcaklıklarda $\left(100^{\circ} \mathrm{C}, 150^{\circ} \mathrm{C}\right.$ ve $\left.200^{\circ} \mathrm{C}\right) 30$ dakika boyunca yongalevha örnekleri ısıl işleme maruz bırakılmaları sonucunda, yoğunluk profilli, eğilme direnci, iç yapışma direnci ve sertlik özelliklerinin etkilendiğini ifade etmişlerdir (Lee ve ark. 2017). Farklı sıcaklıklarda $\left(200^{\circ} \mathrm{C}\right.$, $225^{\circ} \mathrm{C}$ ve $250{ }^{\circ} \mathrm{C}$ ) ve farklı sürelerde ( 5 ve 10 dak.) MDF levhalara uygulanan ısıl işlem sonucunda örneklerin boyutsal stabilizesini iyileştirdiği, fakat eğilme ve eğilmede elastikiyet modülünde azalmaya neden olduğu bildirilmiştir (Oliveira ve ark. 2017).
Literatürde, ahşap esaslı levhalara uygulanan ısıl işlem (post-heat treatment), farklı kaplama veya boyama işlemleri levhaların teknolojik özelliklerini etkilediği bildirilmiştir. Bu çalışmada; elektrostatik toz boya kaplanması esnasında kızılötesi fırın içeresinde levhaların ön ısıtma işlemine maruz bırakılması ve boyanın kürlenmesi için uygulanan sıcaklığın ahşap esaslı levhalara olan bazı fiziksel ve mekanik özelliklere olan etkisi incelenmiştir. Bu amaç doğrultusunda, hibrit esaslı (epoksi / polyester) elektrostatik toz boya ile kaplanmıs ve kaplanmamış MDF ve yongalevhalarda, eğilme direnci, iç yapışma direnci, vida çekme direnci, su alma ve kalınlığına şişme testleri gerçekleştirilmiş ve elde edilen verilerin istatistiksel karşılaştırılması yapılmıştır.

\section{MATERYAL ve YÖNTEM}

\section{Materyal}

TS EN 622-5 (2008) standardına göre çam, kayın ve meşe odunları kullanılarak üretilen $729 \mathrm{~kg} / \mathrm{m}^{3}$ yoğunluğa sahip orta yoğunlukta liflevhalar (MDF) ve TS EN 312 (2005) standardına göre çam, kavak ve meşe odunları kullanılarak üretilen $620 \mathrm{~kg} / \mathrm{m}^{3}$ yoğunluğa sahip yongalevhalar kullanılmıştır. Hibrit esaslı elektrostatik toz boya, İzmir, Türkiye'de faaliyet gösteren toz boya firmasından temin edilmiştir. Hibrit esaslı toz boyanın genel özellikleri Çizelge 1'de verilmiştir. 
Çizelge 1. Hibrit (Epoksi + Polyestyer) esaslı toz boyanın özellikleri

\begin{tabular}{ll}
\hline Toz Boya Özellikleri & Epoksi / Polyester \\
\hline Fiziksel hali & Katı (Toz) \\
Yoğunluk & $1.55-1.65 \mathrm{~g} / \mathrm{cm}^{3}$ \\
Depolama & Kuru Serin Koşullarda $\left(25^{\circ} \mathrm{C}\right.$ Altında) \\
Raf Ömrü & 12 ay \\
Fırınlama Programı & $130^{\circ} \mathrm{C}$, min. 15 dak. - mak. 25 dak. $140^{\circ} \mathrm{C}$, min. 10 \\
Koku & dak. - mak. 25 dak. \\
Bağıl Yoğunluk & Kokusuz \\
Tutuşma Sıcaklı̆̆ı & $1.2-1.9[$ ISO $8130-2 /-3]$ \\
Minimum Tutuşma Enerjisi & $450-600^{\circ} \mathrm{C}$ \\
\hline
\end{tabular}

\section{Yöntem}

$3660 \times 1830 \times 18 \mathrm{~mm}$ ebatlarındaki MDF ve yongalevhalar İstanbul Üniversitesi, Orman fakültesi, mobilya atölyesinde, daire testere makinesi ile $420 \times 250 \mathrm{~mm}$ ebatlarına getirilerek 12 adet MDF ve 12 adet yongalevha olmak üzere toplam 24 adet numune hazırlanmıştır. Numunelerin yarısı elektrostatik toz boya ile kaplanmış, kalan yarısı ise kontrol numunesi (Boyanmamış levhalar) olarak değerlendirilmiştir. Elektrostatik toz boya ile kaplanacak olan örnekler titreşim makinesi ile 150 kum zımpara ile zımparalanmıştır. Zımparalanan örneklerin tozu alındıktan sonra elektrostatik toz boyama işlemine hazır hale getirilmiştir.

Levha yüzeylerinin iletkenlik değerini artırmak için kızılötesi fırında $70{ }^{\circ} \mathrm{C}$ sıcaklıkta 3 dakika boyunca ön ısıtma (Şekil 3a) işlemine tabi tutulmuştur. Ön ısıtmadan çıkan örnek yüzeylerine korona tipi toz boya tabancısı ile hibrit (polyester + epoksi) esaslı elektrostatik toz boya işlemi uygulanmıştır (Şekil 2). Toz boya uygulanmış örnekler kızılötesi fırın içerisinde $130{ }^{\circ} \mathrm{C}$ sıcaklıkta 20 dakika boyunca kürlenmesi sağlanmıştır (Şekil 3b).

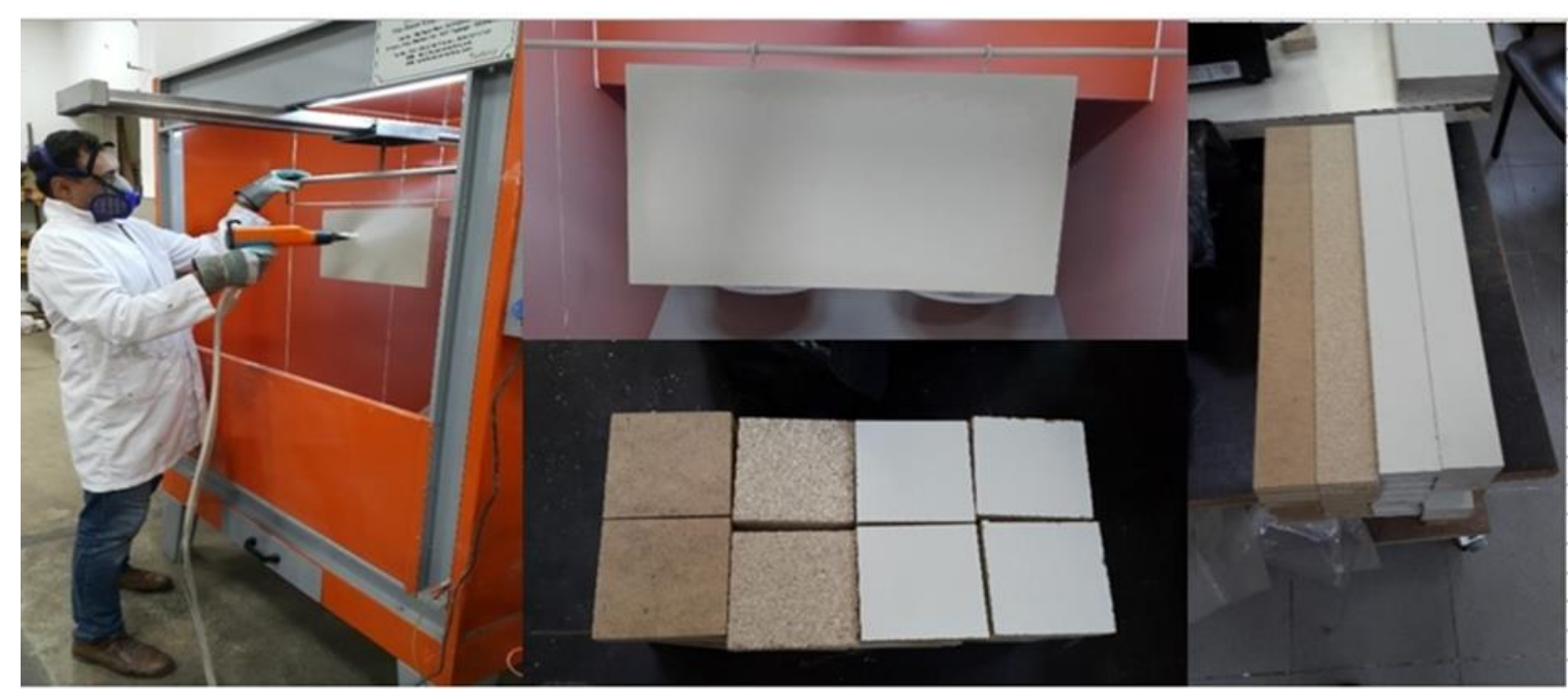

Şekil 2. Elektrostatik toz boya uygulanması ve test örneklerinin hazırlanması

Boyanmış ve boyanmamış levhalar iklimlendirme kabininde $20{ }^{\circ} \mathrm{C}$ sıcaklıkta \% 65 bağıl nem şartlarında ağırlığı değişmez hale gelinceye kadar bekletilmiştir. Kondisyonlanan örnekler, Eğilme direnci TS EN 310
(1999) standartlarına göre 410×50×18 mm ölçülerinde, her bir gruptan 10 adet olmak üzere toplam 40 örnek hazırlanmıştır. Kalınlığına şişme oranı TS EN 317 (1999) standardına göre 50×50×18 mm ölçülerinde ve her bir 


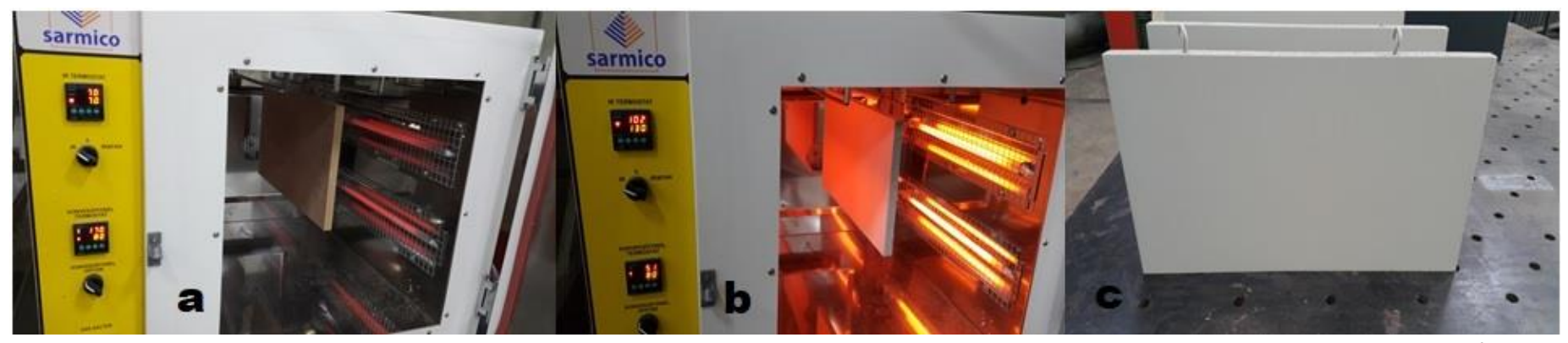

Şekil 2. a. Kızılötesi fırın içerisinde ön ısıtma işlemi b. Kızılötesi fırın içerisinde Toz boyanın kürlenmesi c. Toz boya uygulanmış örnek

gruptan 10 adet olmak üzere toplam 40 adet örnek hazırlanmıştır. Hazırlanan örneklerin ilk kalınlıkları $\left(t_{1}\right)$ ve 24 saat süre sonunda sudan çıktıktan sonra son kalınlıkları $\left(t_{2}\right)$ ölçülerek, $T S=\left(\left(t_{2}-t_{1}\right) / t_{1}\right) \times 100$ formülü ile kalınlığına şişme oranı hesaplanmıştır. Su alma oranı ASTM D 1037 (2012) standardına göre kalınlığına şişme örnekleri üzerinden ilk ağırlıkları $\left(w_{1}\right)$ ve 24 saat süre sonunda sudan çıktıktan sonra son ağırlıkları $\left(w_{2}\right)$ tartılarak, $W A=\left(\left(w_{2}-w_{1}\right) / w_{1}\right) \times 100$ formülü ile su alma oranı hesaplanmıştır. İ̧̧ yapışma direnci TS EN 319 (1999) standardına göre $50 \times 50 \times 18 \mathrm{~mm}$ ölçüsünde her bir gruptan 10 adet olmak üzere toplam 40 adet örnek hazırlanmıştır. Vida çekme direnci TS EN 320 (2011) standardına göre $75 \times 75 \times 18 \mathrm{~mm}$ ebatlarında her gruptan 10 adet olmak üzere toplam 40 örnek hazırlanmıştır. İstatistiksel değerlendirmeler için SPSS 22 istatistik paket programı kullanılmıştır. Varyans analizi ve Duncan testleri sonucunda; boyanmış ve boyanmamış örnek gruplarının eğilme direnci, vida çekme direnci, su alma oranı, kalınlığına şişme oranı ve iç yapışma dirençlerinin istatistiksel karşılaştırılması yapılmıştır.

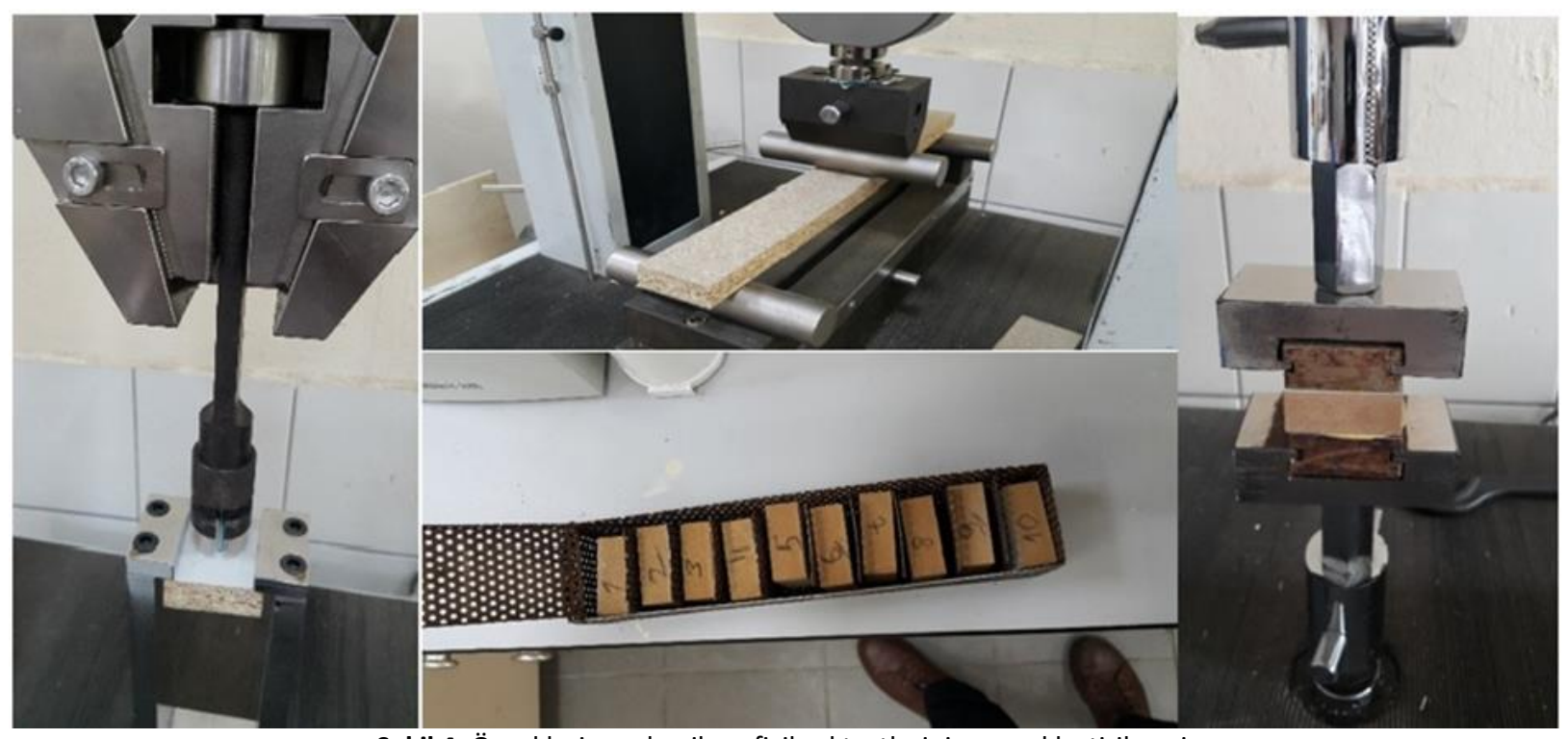

Şekil 4. Örneklerin mekanik ve fiziksel testlerinin gerçekleştirilmesi.

\section{BULGULAR ve TARTIŞMA}

Elektrostatik toz boya ile kaplanmış ve kaplanmamış MDF ve yongalevha örneklerinin, vida çekme, iç yapışma direnci, eğilme direnci, 24 saat suda bekletme sonucunda su alma ve kalınlığına şişme oranlarının istatiksel karşılaştırılması Çizelge 2'de belirtilmiştir.

Elektrostatik toz boya ile kaplanmış ve kaplanmamış yongalevha ve MDF örneklerinin vida çekme direnç değerlerinin karşılaştırtılması Şekil 5'de belirtilmiştir.
Yapılan analizler sonucunda vida çekme direnci en yüksek toz boya uygulanmış MDF numunelerinde (993 N) elde edilmiştir. Toz boya ile kaplanmış MDF ve kaplanmamış MDF örnekler arasında istatistiksel bir farklılık bulunmamıştır. Vida çekme direnci en düşük toz boya uygulanmış yongalevha örneklerinde $(692 \mathrm{~N})$ tespit edilmiştir. Yongalevhaların toz boya ile kaplanması sonucunda levha yüzeyine dik vida çekme direncini düşürdüğü belirlenmiştir. Bu durum yongalevhaların, 
Çizelge 2. Levhalara uygulanan testlerin istatistiksel karşılaştırılması

\begin{tabular}{|c|c|c|c|c|c|}
\hline Malzemeler & $\begin{array}{l}\text { Vida Çekme } \\
\text { Direnci (N) }\end{array}$ & $\begin{array}{c}\text { İç Yapışma } \\
\text { Direnci }\left(\mathrm{N} / \mathrm{mm}^{2}\right)\end{array}$ & $\begin{array}{l}\text { Eğilme Direnci } \\
\left(\mathrm{N} / \mathrm{mm}^{2}\right)\end{array}$ & Su alma (\%) & $\begin{array}{l}\text { Kalınlığına } \\
\text { Şişme (\%) }\end{array}$ \\
\hline $\begin{array}{l}\text { Boyanmış } \\
\text { Yongalevha }\end{array}$ & $\begin{array}{l}692.91^{c} \\
(58.62)\end{array}$ & $\begin{array}{l}0.20^{c} \\
(0.05)\end{array}$ & $\begin{array}{l}12.13^{\mathrm{d}} \\
(0.23)\end{array}$ & $\begin{array}{l}91.11^{\mathrm{a}} \\
(2.08) \\
\end{array}$ & $\begin{array}{l}15.04^{b} \\
(0.58)\end{array}$ \\
\hline Yongalevha & $\begin{array}{l}817.56^{b} \\
(60.16)\end{array}$ & $\begin{array}{l}0.36^{\mathrm{b}} \\
(0.06)\end{array}$ & $\begin{array}{l}13.57^{c} \\
(0.33)\end{array}$ & $\begin{array}{l}79.63^{b} \\
(4.90)\end{array}$ & $\begin{array}{l}16.17^{a} \\
(0.62)\end{array}$ \\
\hline Boyanmış MDF & $\begin{array}{l}993.12^{\mathrm{a}} \\
(71.19)\end{array}$ & $\begin{array}{l}0.52^{\mathrm{a}} \\
(0.05)\end{array}$ & $\begin{array}{l}20.92^{b} \\
(0.62)\end{array}$ & $\begin{array}{l}11.72^{c} \\
(1.72)\end{array}$ & $\begin{array}{l}1.30^{\mathrm{d}} \\
(0.24)\end{array}$ \\
\hline MDF & $\begin{array}{l}970.04^{a} \\
(81.39)\end{array}$ & $\begin{array}{l}0.58^{\mathrm{a}} \\
(0.03)\end{array}$ & $\begin{array}{l}22.98^{a} \\
(2.47)\end{array}$ & $\begin{array}{l}11.71^{c} \\
(0.36)\end{array}$ & $\begin{array}{l}3.18^{c} \\
(0.16)\end{array}$ \\
\hline
\end{tabular}

MDF'ye göre daha gözenekli bir yapıya sahip olması ve kızılötesi ışınların gözenekler içerisine daha fazla derinliğe girmesi ile yoğun sıcaklığa maruz kalan üre formaldehit tutkalının bağlayıcı matrisindeki bozunmalardan kaynaklanmış olabileceği düşünülmektedir. Ayrıca toz boya uygulaması esnasında sıcaklığın etkisi ile yongalevha kenarlarında meydana gelen kılcal çatlaklıklar vida çekme direncini olumsuz etkilemiştir. Melo ve ark. (2018) $160{ }^{\circ} \mathrm{C}$ ve $180^{\circ} \mathrm{C}$ sıcaklıkta, 6 ve 12 dakika süre ile ısıl işlem maruz bırakılan yongalevharın vida çekme direncinin düştüğü, fakat \%95 güven düzeyinde istatistiksel olarak anlamlı bir farklılık olmadığını belirtmişlerdir. Ayrılmış (2010) farklı sıcaklıklar $\left(175^{\circ} \mathrm{C}, 200^{\circ} \mathrm{C}\right.$ ve $\left.225^{\circ} \mathrm{C}\right)$ ve farklı periyotlarda (15 ve 30 dak.) MDF örneklere uyguladığı ısıl işlem sonucunda sıcaklığın yükselmesi ile birlikte vida çekme direncinin düştüğünü ifade etmiştir. Wandscheer ve ark. (2016) $160^{\circ} \mathrm{C}$ ve $180^{\circ} \mathrm{C}$ sıcaklılarda 6 ve 12 dakika süre boyunca ısıl işleme maruz bıraktıkları MDF grubu ile MDF kontrol (ısıl işlem uygulanmamış) grupları arasında vida çekme direncinin istatistiksel olarak anlamlı bir farklılık bulunmadığını belirtmişlerdir. Ayrıca literatürde malzeme yoğunluğunun vida çekme direncini önemli derecede etki ettiği ve levha üretiminde kullanılan ağaç türünden ziyade üretim süreci ile ilişkili olduğu ifade edilmiştir (Wang ve ark. 2007; Erdil ve ark. 2003). MDF'nin vida çekme direnci yongalevhadan daha yüksek olduğu ve yongalevhaların yoğunluğun artması ile vida çekme direncinin artırdığı bildirilmiştir (Çolakoğlu 2009; Vassiliou 2005; Chen ve ark. 2016). Ahşap kaplama ile kaplanan yongalevhaların vida çekme direnci, melamin reçine emdirilmiş kağıt ile kaplanmış yongalevhadan daha yüksek olduğu belirtilmiştir (Vassiliou 2005). Literatürde, ahşap esaslı levhaların, ahşap kaplama, CPL (Sürekli pres laminat) ve HPL (Yüksek pres laminat) gibi pres basıncı altında kaplanması

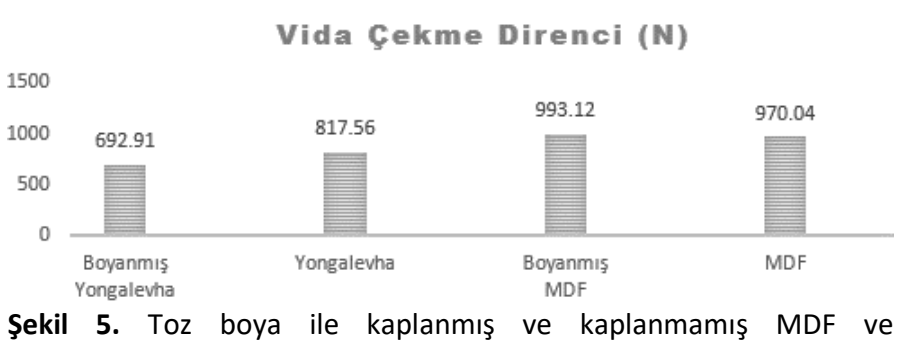
yongalevhaların vida çekme direnci

sürecinde uygulanan yüksek basınç, levhaların yoğunlaşmasına (densification) neden olduğu ve dolayısıyla bazı teknolojik özelliklerin yüksek çıkmasında etkili olduğu düşünülmektedir.

Toz boya ile kaplanmış ve kaplanmamış örneklerin iş yapışma direnci sonuçlarının karşılaştırılması Şekil 6'da verilmiştir.

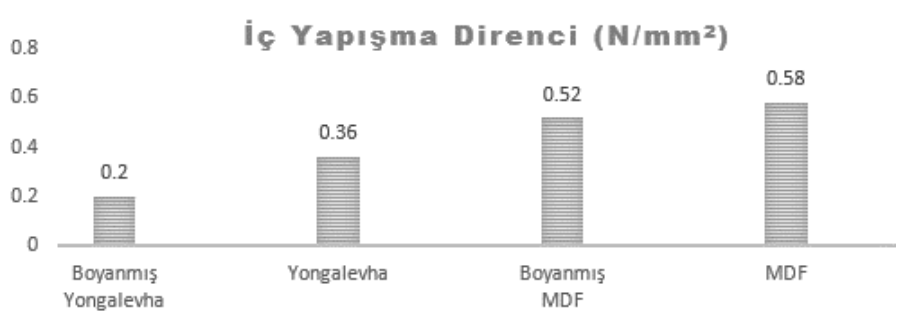

Şekil 6. Toz boya uygulanmış ve uygulanmamış MDF ve yongalevha örneklerinin iç yapışma direnci

İ̧ yapışma direnci en yüksek, kaplanmamış MDF örneklerinde $\left(0.58 \mathrm{~N} / \mathrm{mm}^{2}\right)$, en düşük ise elektrostatik toz boya ile kaplanmış yongalevha örneklerinde $(0.20$ $\mathrm{N} / \mathrm{mm}^{2}$ ) elde edilmiştir. İstatistiksel olarak toz boya ile kaplanmış MDF örnekleri $\left(0.58 \mathrm{~N} / \mathrm{mm}^{2}\right)$ ile, kaplanmamış MDF örnekleri $\left(0.52 \mathrm{~N} / \mathrm{mm}^{2}\right)$ arasında anlamlı bir fark bulunmamıştır. Elektrostatik toz boya kaplama işlemi, MDF örneklerinde iç yapışma direncini etkilemezken, yongalevha örneklerinde olumsuz yönde etkilediği tespit edilmiştir. Yongalevhaların gözenekli yapısı ve boya uygulama sürecinde $70{ }^{\circ} \mathrm{C}$ sıcaklıkta ön ısıtma ve $130{ }^{\circ} \mathrm{C}$ 
sıcaklıkta kürlenme işlemleri yongalevhanın iç yapışma direncini etkilediği düşünülmektedir. Oliveira ve ark. (2017) yüksek sıcaklıklarda $\left(200^{\circ} \mathrm{C}, 225^{\circ} \mathrm{C}\right.$ ve $\left.250^{\circ} \mathrm{C}\right)$ ve sürelerde (5 ve 10 dak.) Isıl işleme maruz bıraktıkları MDF örneklerinin, ısıl işlem sıcaklığı ve sürenin artması ile levha içerisinde kullanılan üre formaldehit tutkalın bozunması sonucunda, levhaların iç yapışma direncini olumsuz yönde etkilediğini bildirmişledir. Lee ve ark. (2017) farklı sıcaklıklarda $\left(100^{\circ} \mathrm{C}, 150^{\circ} \mathrm{C}\right.$ ve $\left.200^{\circ} \mathrm{C}\right) 30$ dakika boyunca yongalevha örneklerini ısıl işleme maruz bırakılmaları sonucunda, $100{ }^{\circ} \mathrm{C}$ ve $150{ }^{\circ} \mathrm{C}$ sıcaklıklarda iç yapışma direnci etkilenmezken, $200{ }^{\circ} \mathrm{C}$ sıcaklıkta levhanın iç yapışma direnci olumsuz etkilendiğini ifade etmişlerdir. Levha iç yapışma direnci, tutkal ve tutkallama kalitesini belirleyen en önemli özelliktir. Levha, iç yapışma direnci, üretimde kullanılan yöntem, yonga geometrisi, tutkal miktarına da bağlıdır. Genellikle tutkal miktarının artması ile bu direnç değeri de artmaktadır. Bu direnç değeri levhanın yoğunluğuna bağı olarak bir yükselme göstermektedir (Yılmaz ve Yener 1990).

Toz boya ile kaplanmış ve kaplanmamış örneklerin eğilme direnci sonuçlarının karşılaştırılması Şekil 7'de verilmiştir.

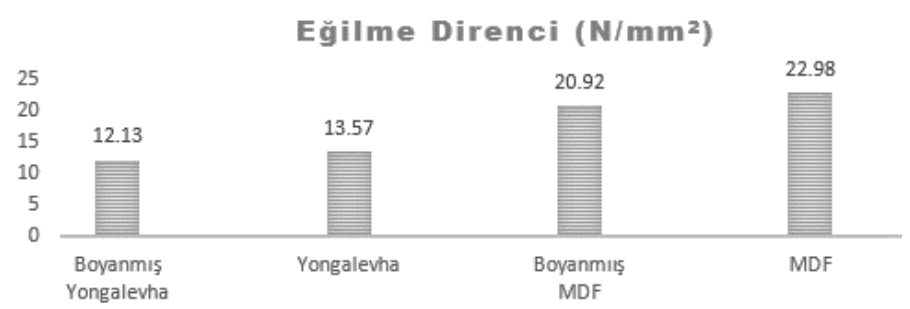

Şekil 3. Toz boya uygulanmış ve uygulanmamış MDF ve yongalevha örneklerinin eğilme direnci

Eğilme direnci kaplanmamış MDF örneklerinde 22.98 $\mathrm{N} / \mathrm{mm}^{2}$, kaplanmamış yongalevha grubunda 13.57 $\mathrm{N} / \mathrm{mm}^{2}$, elektrostatik toz boya uygulanmış MDF grubunda $20.92 \mathrm{~N} / \mathrm{mm}^{2}$, yongalevha grubunda ise $12.13 \mathrm{~N} / \mathrm{mm}^{2}$ tespit edilmiştir. MDF ve yongalevha yüzeylerine elektrostatik toz boya kaplama sürecinde uygulanan sıcaklıklar levhanın eğilme direncini olumsuz yönde etkilemiştir. Yüksek sıcaklıklar $\left(180^{\circ} \mathrm{C}\right.$ ve $\left.200^{\circ} \mathrm{C}\right)$ ve yüksek sürelerde ( 3 ve 5 saat) MDF levhalara uygulanan ısıl işlem, eğilme direncini olumsuz yönde etkilendiğini ifade etmiştir. (Lunguleasa 2015). Farklı sıcaklıklarda $\left(155{ }^{\circ} \mathrm{C}\right.$, $165^{\circ} \mathrm{C}$ ve $\left.175^{\circ} \mathrm{C}\right)$ ve farklı sürelerde $(2.5,3.5$ ve 4.5 saat) MDF levhalara uygulanan ısıl işlem sonucunda eğilme direnci ve eğilmede elastikiyet modülü olumsuz etkilendiği bildirilmiştir (Ateş ve ark. 2017). Dış ortam şartlarında kullanılan MDF örneklerine yapılan ısıl işlem sonucunda, ısıl işlem sıcaklığının artması ile birlikte eğilme direncinde azalma meydana gelmiştir (Ayrılmış ve ark.
2009). Yongalevha ve MDF örneklerine $140{ }^{\circ} \mathrm{C}$ sıcaklıkta bir saat süre ile ısıl işleme maruz kalması sonucunda eğilme direnci değerinin, yongalevhada \% 40, MDF'de \% 37 oranında azaldığı ifade edilmiştir (Bekhta ve ark. 2003). Literatürde yongalevha yüzeyleri, lake boyama, melamin reçine emdirilmiş kağıt, ahşap kaplama ve CPL (Sürekli pres laminat) ile kaplanması sonucunda örneklerin eğilme direncinde artış olduğu ifade edilmiştir (Nemli ve ark. 2005, Nemli ve Çolakoğlu 2005, İstek ve ark. 2010). Bu çalışmalarda kullanılan kaplama kalığının yüksek olması, basınç altında levhaların kaplanması, eğilme direncinin yüksek çıkmasında etkili nedenler arasında gösterilebilir. Yongalevhalarda eğilme direnci, levha yoğunluğunun artması ile artığı da bildirilmiştir (Yılmaz ve Yener 1990).

Toz boya ile kaplanmış ve kaplanmamış örneklerin su alma oranlarının karşılaştırılması Şekil 8'de verilmiştir.

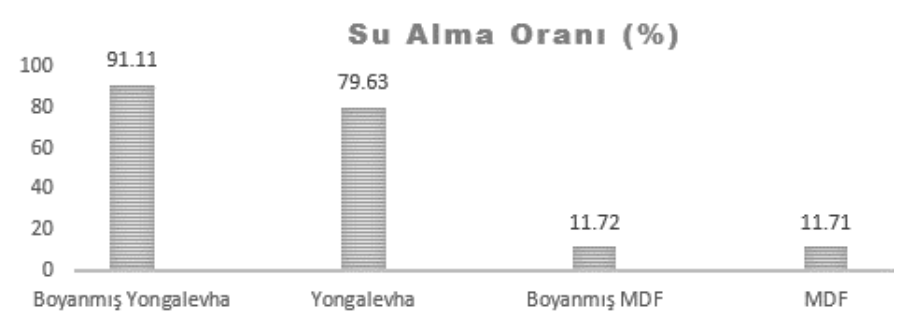

Şekil 8. Toz boya uygulanmış ve uygulanmamış MDF ve yongalevha örneklerinin su alma oranı

Kaplanmış ve kaplanmamış yongalevha ve MDF örnekleri, 24 saat su içerisinde bekletilmesi sonucunda; su alma oranı en yüksek toz boya uygulanmış yongalevha örneklerinde (\% 91.11), en düşük ise kaplanmamış MDF örneklerinde (\% 11.71) tespit edilmiştir. Toz boya ile kaplanmış MDF örnekleri ile kaplanmamış MDF örnekleri arasında istatistiksel bir fark bulunmamıştır. Kaplanmamış yongalevha örneklerinin su alma oranı, toz boya ile kaplanmış yongalevha örneklerinden daha düşük çıkmıştır. Bu durum elektrostatik toz boya uygulaması esnasında sıcaklığın etkisi ile levha kenarlarında meydana gelen kılcal çatlaklılardan kaynaklanmış olabilir. Farklı sıcaklıkta $\left(155^{\circ} \mathrm{C}, 165^{\circ} \mathrm{C}\right.$ ve $\left.175^{\circ} \mathrm{C}\right)$ ve farklı sürelerde (2.5, 3.5 ve 4.5 saat) MDF levhalara uygulanan ısıl işlem sonucunda su alma oranını olumlu yönde etkilediği ifade edilmiştir (Ateş ve ark. 2017). Dış ortam şartlarında kullanılan MDF örneklerine yapılan ısıl işlemin su alma oranında artışa neden olduğu bildirilmiştir (Ayrılmış 2009). MDF yüzeylerini PVC folyolarla memran ve wrapping metodları kaplaması sonucunda su alma oranını iyileştirdiği bildirilmiştir (Kayıs 2016). Üre-melamin reçine emdirilmiş dekor kâğıdı kaplanmış MDF örnekleri ile kaplanmamış MDF örneklerini aynı koşullarda 1 saat, 1 gün, 1 hafta, 1 ay ve 3 ay bekletmesi sonucunda, 
kaplanmış MDF grubunda depolama süresini artması ile su alma oranında artış meydana gelirken, kaplanmamış MDF örneklerinde azalma olduğu ifade edilmiştir (Özçifçi ve ark. 2016). Ahşap esaslı levhaların üretim metodu ve üretim parametreleri, kaplama türü, kaplamının kalınlığı ve kaplamanın uygulama metodu, levhaların su alma oranlarında değişikliğe neden olmaktadır.

Toz boya kaplanmış ve kaplanmamış örneklerin su alma sonucunda kalınlığına şişme değerlerinin karşılaştırılması Şekil 9'da verilmiştir.

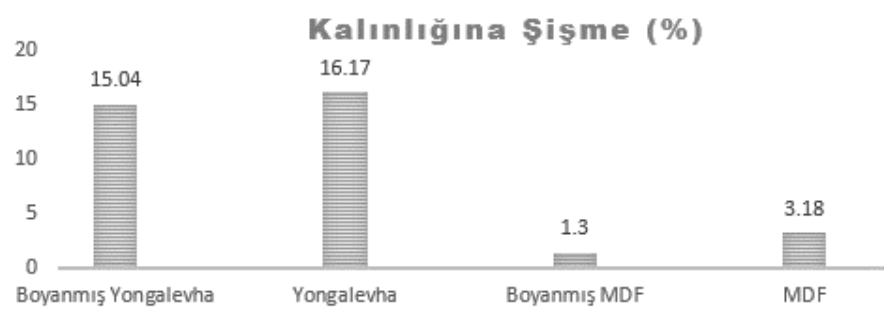

Şekil 9. Toz boya uygulanmış ve uygulanmamış MDF ve yongalevha örneklerinin kalınlığına şişme oranı.

Su alma sonucunda levhalarda meydana gelen kalınlığına şişme oranı en yüksek ham yongalevha örneklerinde (\%16.17), en düşük ise toz boya kaplanmış MDF örneklerinde (\% 1.3) elde edilmiştir. Kaplanmamış MDF örneklerinde su alma oranı \% 3.18, kaplanmış yongalevhada bu oranı \% 15.04 olarak tespit edilmiştir. Elektrostatik toz boya uygulaması, hem yongalevha hem de MDF örneklerinde kalınlığına şişme değerlerini iyileştirdiği tespit edilmiştir. Literatürde, ahşap esaslı levhaların çeşitli kaplama türleri ile kaplanması sonucunda kalınlığına şişme oranlarını iyileştirdiği bildirilmiştir (Nemli ve Çolakoğlu 2005, Nemli ve ark. 2005, ístek ve ark. 2010). Farklı sıcaklıklarda $\left(155^{\circ} \mathrm{C}, 165\right.$ ${ }^{\circ} \mathrm{C}$ ve $\left.175^{\circ} \mathrm{C}\right)$ ve farklı sürelerde $(2.5,3.5$ ve 4.5 saat) MDF levhalara uygulanan ısıl işlemin kalınlığına şişme oranını iyileştirdiği bildirilmiştir (Ateş ve ark. 2017). Dış ortam şartlarında kullanılan MDF örneklerine uygulanan ısıl işlem kalınlığına şişme oranını olumlu yönde etkilediği ifade edilmiştir (Ayrılmış ve ark. 2009). Farklı sıcaklıklarda $\left(200{ }^{\circ} \mathrm{C}, 225^{\circ} \mathrm{C}\right.$ ve $250{ }^{\circ} \mathrm{C}$ ) ve farklı sürelerde (5 ve 10 dakika) MDF levhalara uygulanan ısıl işlem sonucunda, örneklerin boyutsal stabilizesini iyileştirdiği belirtilmiştir (Oliveira ve ark. 2017). Farkı sıcaklık ve sürelerde ısıl işlem uyguladıkları MDF örneklerinde su alma ve kalınlığına şişme değerlerinin daha düşük olduğunu belirtmişlerdir (Lunguleasa ve Spirchez 2015). Toz boya uygulanmış MDF ve yongalevha örnekleri bünyesine daha fazla su almasına rağmen kalınlığına şişme oranları daha düşük çıktığı tespit edilmiştir. Bu durum, elektrostatik toz boya uygulaması esnasında levhaların ısıl işleme maruz kalmasından kaynaklandığı düşünülmektedir. Literatürde, Isıl işlem görmüş ağaç malzemelerde hemiselülozun parçalaması sonucu hidroksil grupların azalmasına neden olduğu ve malzemenin higroskopitesinin (nem alıp vermesine bağlı olarak malzemede meydana gelen boyutsal değişiklik) düşmesi ile açıklanmaktadır.

\section{SONUÇ}

Son zamanlarda solvent esaslı sıvı boyalara göre, elektrostatik toz boyalar çevre, iş güvenliği ve işçi sağlığı açısından sağlamış olduğu avantajlardan dolayı, ahşap ve ahşap esaslı kompozit levhalarda kullanımı, uygulama ve araştırma çalışmaları büyük bir ivme kazanmaktadır. Bu çalışmada, ahşap esaslı levha yüzeylerine uygulanan elektrostatik toz boyalar, levhaların mekanik ve fiziksel özellikleri üzerindeki etkisi belirlenmeye çalışılmıştır. Çalışma sonucunda, MDF yüzeylere elektrostatik toz boya uygulaması sonucunda, kalınlığına şişme oranını iyileştirdiği ve vida çekme direnci, iç yapışma direnci, su alma oranı bakımından kaplanmamıs örnekler arasında istatistiksel bir fark bulunmamıştır. Fakat toz boya uygulanmış MDF örneklerinde eğilme direnci \% 8.9 oranında azalma tespit edilmiştir. Yongalevha yüzeylerine uygulanan elektrostatik toz boya işlemi sonucunda, kalınlığına şişme oranını iyileştirdiği, fakat vida çekme direnci, iç yapışma direnci, eğilme direnci ve su alma oranlarını negatif yönde etkilediği tespit edilmiştir. elektrostatik toz boya uygulaması sonucunda, MDF'nin teknolojik özellikleri üzerinde çok fazla olumsuz bir etkisi bulunmazken, yongalevha örneklerini olumsuz yönde etkilediği tespit edilmiştir. Yongalevha yüzeylerine uygulanacak elektrostatik toz boya işleminde sıcaklık ve sürenin azaltılması büyük önem arz etmektedir.

\section{KAYNAKLAR}

Akkus M, Akbulut T, Candan Z (2019) Application of electrostatic powder coating on wood composite panels using a cooling method. Part 1: Investigation of water intake, abrasion, scratch resistance, and adhesion strength. BioResources 14(4): 9557-9574

Akkus M, Akbulut T, Candan Z (2021) Formaldehyde emission, combustion behavior, and artificial weathering characteristics of electrostatic powder coated wood composite panels. Wood Material Science \& Engineering 1-11

Altuntaş M (2012) Yalıtkan ürünlerin elektrostatik toz boya ile boyanmasına olanak veren astar boya karışımı. Türk Patent Enstitüsü, Patent No: 2012/07395

ASTM D 1037 (2012) Standard methods of evaluating the properties of wood - based

fiber and particle panel materials. Philadelphi, PA. USA.

Ates S, Kara HR, Olgun C, Ozkan OE (2017) Effects of heat treatment on some properties of MDF (Medium-Density Fiberboard). Wood Material Science \& Engineering 12(3): 158-164 
Ayrilmis N (2020) Surface properties of oriented strand board coated by electrostatic dry powder spray deposition technique. BioResources 15(1): 1521-1530

Ayrilmis N, Laufenberg TL, Winandy JE (2009) Dimensional stability and creep behavior of heat-treated exterior medium density fiberboard. European Journal of Wood and Wood Products 67(3): 287-295

Ayrilmis, N (2010) Variations in hardness and screw withdrawal resistance of heat treated medium density fiberboards. Wood Research 55(1) 111-116

Badila M, Jocham C, Zhang W, Schmidt T, Wuzella G, Müller U, Kandelbauer A (2014) Powder coating of veneered particle board surfaces by hot pressing. Progress in Organic Coatings 77(10): 1547-1553

Bekhta P, Lecka J, Morze Z (2003) Short-term effect of the temperature on the bending strength of wood-based panels. Holz als Roh-und Werkstoff 61(6): 423-424

Chen Y, Zhu S, Guo Y, Liu S, Tu D, Fan H (2016) Investigation on withdrawal resistance of screws in reconstituted bamboo lumber. Wood Research 61(5): 799-810

Colakoglu MH (2009) Determination of bending strength elongation in bending screw withdrawal strength and swelling in thickness of some panels. Journal of Applied Sciences 9(22): 4061-4065

Erdil YZ, Zhang J, Eckelman CA (2003) Staple holding strength of furniture frame joints constructed of plywood and oriented strandboard. Forest Products Journal 53(1): 70-75

Gioia CA, Minesso R, Cavalieri P, Marchese, A, Celli M, Colonna M (2015) Powder coatings for indoor applications from renewable resources and recycled polymers. Journal of Coatings Technology and Research 12(3): 555-562

Istek A, Aydemir D, Aksu S (2010) The effect of decor paper and resin type on the physical, mechanical, and surface quality properties of particleboards coated with impregnated décor papers. BioResources 5(2): 1074-1083

İstek A, Özlüsoylu i, Aydın U (2016) The Effect of resin paper coating on some particleboard properties. Internatinal Conference on Engineering and Natural Sciences, Sarajevo, pp 1312-1317

Jocham C, Schmidt TW, Wuzella G, Teischinger A, Kandelbauer A (2011) Adhesion improvement of powder coating on medium density fibreboard (MDF) by thermal pre-treatment. Journal of Adhesion Science and Technology 25(15): 1937-1946

Kayıs S, Bektas I, Ak AK (2016) Comparing the technological properties of mdf's coated with pvc folios using wrapping and membrane press methods. II. Internatıonal Furniture Congress, Muğla, pp 258-262

Knoblauch M (2013) The Future of Industrial Coatings UV-curable powder coating for MDF wood. Paint and Coatings Industry 25(13): 34-36

Köhler R, Sauerbier P, Militz H, Viöl W (2017) Atmospheric pressure plasma coating of wood and mdf with polyester powder. Coatings 7(10): 171

Lee SH, Lum WC, Zaidon A, Fatin-Ruzanna J, Tan LP, Mariusz M, Chin KL (2017) Effect of post-thermal treatment on the density profile of rubberwood particleboard and its relation to mechanical properties. Journal of Tropical Forest Science 29(1): 93-104

Liberto N (2003) User's guide to powder coating. Society of Manufacturing Engineers, ISBN-10: 0872636488.

Lunguleasa, A, Spîrchez C, (2015) The characteristics of thermally treated mdf panels. Bulletin of the Transilvania University of Brasov 8(2): 55-60
Melo RR, Muhl M, Stangerlin DM, Alfenas RF, Rodolfo F (2018) "Properties of particleboards submitted to heat treatments. Ciência Florestal 28(2): 776-783

Nemli G, Çolakoğlu G (2005) The Influence of lamination technique on the properties of particleboard. Building and Environment 40(1): 83-87

Nemli G, Hiziroglu S (2009) Effect of press parameters on scratch and abrasion resistance of overlaid particleboard panels. Journal of Composite Materials 43(13): 1413-1420

Nemli G, Örs Y, Kalaycıoğlu H (2005) The choosing of suitable decorative surface coating material types for interior end use applications of particleboard. Construction and Building Materials 19(4): 307-312

Oliveira SL, Freire TP, Mendes LM, Mendes RF (2017) The Effect of post-heat treatment in mdf panels. Materials Research 20(1) 183190

Oliveira SL, Freire TP, Mendes LM, Mendes RF (2017) The effect of post-heat treatment in MDF panels. Materials Research 20(1): 183-190

Özçifci A, Kara ME, Karakaya B (2016) Effect of storage time on some mechanical and physical properties of melamine coated MDFs," II. Internatıonal Furnıture Congress, Muğla, pp 197-203

TS EN 310 (1999) Ahşap esaslı levhalar-eğilme dayanımı ve eğilme elastikiyet modülünün tayini. Türk Standartlar Enstitüsü, ICS 79.060 .01

TS EN 312 (2005) Yonga levhalar - özellikler. Türk Standartlar Enstitüsü, ICS 79.060.20

TS EN 317 (1999) Yonga levhalar ve lif levhalar-su içerisine daldırma işleminden sonra kalınlığına şişme tayini. Türk Standartlar Enstitüsü, ICS 79.060.20

TS EN 319 (1999) Yonga levhalar ve lif levhalar-levha yüzeyine dik çekme dayanımının tayini. Türk Standartlar Enstitüsü, ICS 79.060 .20

TS EN 320 (2011) Yonga levhalar ve lif levhalar-vida tutma mukavemetinin tayini. Türk Standartlar Enstitüsü, ICS 79.060.20

TS EN 622 - 5 (2008) Lif levhalar - özellikler - bölüm 5: Kuru işlemli levhalar (MDF) için gerekler. Türk Standartlar Enstitüsü, ICS 79.060.20

Tunçgenç M (2014) Genel boya bilgileri. Teknik Bülten, Akzo Nobel Kemipol A.Ş.

Utech BA (2002) Guide to high-performance powder coating, Society of Manufacturing Engineers, ISBN-10: 0872635457.

Vassiliou V, Barboutis I (2005) Screw withdrawal capacity used in the eccentric joints of cabinet furniture connectors in particleboard and MDF. Journal of Wood Science 51(6): 572-576

Wandscheer RB, Bressan, J, Melo RR, Lima DC, Pedrosa TD, Ferreira MD (2016) Thermal treatment effect on physical and mechanical properties of mdf panels. Nativa 4(2): 71-76

Wang XA, Salenikovich A, Mohammad M (2007) Localized density effects on fastener holding capacities in wood-based panels. Forest Products Journal 57(1/2): 103-109

Wuzella G, Kandelbauer A, Mahendran AR, Teischinger A (2011) Thermochemical and isoconversional kinetic analysis of a polyester-epoxy hybrid powder coating resin for wood based panel finishing. Progress in Organic Coatings 70(4): 186-191

Yılmaz B, Yener G (1990) Yongalevha endüstrisi. İstanbul Üniversitesi, Orman Fakültesi Yayını, İstanbul 